\title{
Aplikasi Transformasi Laplace Pada Rangkaian Listrik
}

\author{
Arifin, Muhammad Wakhid Musthofa, dan Sugiyanto \\ Program Studi Matematika Fakultas Sains dan Teknologi, UIN Sunan Kalijaga, Jl. Marsda Adisucipto \\ No. 1 Yogyakarta, Indonesia
}

Korespondensi; Sugiyanto, Email: sugimath@yahoo.com

\begin{abstract}
Abstrak
Menyelesaikan persamaan diferensial sering terkendala oleh masalah syarat awal atau syarat batas. Masalah syarat batas ini sering dijumpai pada penerapan persamaan diferensial, salah satunya adalah rangkaian listrik. Metode yang dapat digunakan untuk menyelesaikan masalah syarat batas pada persamaan diferensial salah satu diantaranya adalah metode transformasi Laplace. Transformasi Laplace yang didefinisikan dengan $\mathcal{L}\{f(t)\}=\int_{0}^{\infty} e^{-s t} f(t) d t$ dapat digunakan untuk mencari solusi dari suatu sistem persamaan diferensial koefisien konstan. Metode penyelesaian suatu rangkaian Listrik dengan menggunakan transformasi Laplace adalah dengan mengubah persamaan diferensial dari domain waktu $(t)$ ke dalam domain frekuensi $(s)$, memetakan masalah nilai awal ke dalam persamaan pembantu, menyelesaikan dengan perhitungan aljabar, dan menggunakan invers transformasi Laplace untuk mendapatkan solusi khusus secara langsung dari sistem persamaan diferensial rangkaian listrik tersebut.
\end{abstract}

Kata Kunci: Transformasi Laplace; invers transformasi Laplace; persamaan diferensial orde dua koefisien konstan; rangkaian listrik

\begin{abstract}
Resolving differential equations is often constrained by problems of initial requirements or boundary conditions. The problem of boundary conditions is often found in the application of differential equations, one of which is the electrical circuit. The method that can be used to solve the problem of boundary conditions on the differential equation is one of them is the Laplace transform method. Laplace transforms defined by $\mathcal{L}\{f(t)\}=\int_{0}^{\infty} e^{-s t} f(t) d t$ can be used to find the solution of a system of constant coefficient differential equations. The method of completion of an electrical circuit by using Laplace transform is by changing the differential equation of the time domain $(t)$ into the frequency domain $(s)$, mapping the initial value problem into the helper equation, solving it by algebraic calculation, and using Laplace inverse transformation to obtain the solution Specifically directly from the system of differential equations of the electrical circuit.
\end{abstract}

Keywords: Laplace transform; Inverse Laplace transform; Two-order differential equations coefficient constant; electrical circuit

\section{Pendahuluan}

Metode Transformasi Laplace (Laplace Transformation) merupakan suatu metode yang dapat digunakan untuk menyelesaikan persamaan diferensial, yang memetakan masalah nilai awal ke dalam suatu persamaan aljabar atau suatu sistem persamaan yang dapat diselesaikan dengan metode aljabar dan tabel transformasi Laplace. Metode ini pertama kali diperkenalkan oleh Pierre Simon Marquas De Laplace (1749 1827) seorang matematikawan Perancis dan seorang guru besar di Paris. Dengan metode transformasi Laplace akan dihasilkan solusi khusus secara langsung sesuai dengan kondisi masalah nilai awal yang diberikan.

Rangkaian listrik adalah suatu kumpulan elemen atau komponen listrik yang saling dihubungkan dengan cara-cara tertentu dan paling sedikit mempunyai satu lintasan tertutup. Suatu rangkaian listrik dapat dimodelkan ke dalam suatu persamaan diferensial, yaitu persamaan diferensial orde dua koefisien konstan. Oleh sebab itu, solusi rangkaian listrik tersebut dapat ditentukan dengan menggunakan 
transformasi Laplace. Namun, ada suatu rangkaian yang tidak menimbulkan masalah atau kesulitan untuk dianalisa dengan matematika biasa, yaitu rangkaian yang hanya memuat satu elemen rangkaian listrik. Elemen rangkaian listrik dapat dikelompokkan ke dalam elemen atau komponen aktif dan pasif. Elemen aktif adalah elemen yang menghasilkan energi, dalam hal ini adalah sumber tegangan dan sumber arus. Elemen lain adalah elemen pasif dimana elemen ini tidak dapat menghasilkan energi, yaitu elemen yang hanya dapat menyerap energi (resistor), elemen yang dapat menyimpan energi (induktor) dan elemen yang menyerap energi dalam bentuk medan magnet (kapasitor). Suatu rangkaian yang sulit dapat dianalisis/diselesaikan dengan menggunakan transformasi Laplace. Hal ini disebabkan oleh karakteristik dari tiap-tiap elemen rangkaian listrik yang berbeda meskipun secara definitive $v_{R}, v_{L}$ dan $v_{C}$ adalah besarnya arus yang mengalir pada elemen $\mathrm{R}, \mathrm{L}$, dan $\mathrm{C}$.

\section{Penyelesaian Persamaan Diferensial Dengan Transformasi Laplace}

Penerapan yang cukup penting dari transformasi Laplace salah satunya adalah untuk menentukan penyelesaian persamaan diferensial linear dengan koefisien kostan. Dalam skripsi ini hanya dibatasi pada persamaan diferensial orde dua koefisien konstan.

Metode transformasi Laplace secara khusus digunakan untuk menyelesaikan persamaan diferensial dan memenuhi syarat awal. Untuk menyelesaikan persamaan diferensial ini adalah dengan mengambil transformasi Laplace dari persamaan diferensial yang diberikan, lalu menggunakan syarat-syarat awalnya. Ini memberikan suatu persamaan aljabar dalam transformasi Laplace dari penyelesaian yang diinginkan. Dengan mengambil invers dari transformasi Laplace yang telah dibentuk maka diperoleh penyelesaiannya.

Berikut ini diberikan prosedur/ langkah-langkah mencari penyelesaian suatu persamaan diferensial linear orde dua berkoefisien konstan menggunakan transformasi Laplace (John Bird, 2007: 637).

Diberikan suatu persamaan diferensial linear orde dua, yaitu:

$$
a y^{\prime \prime}+b y^{\prime}+c y=r(t)
$$

Dengan syarat awal $y(0)$ dan $y^{\prime}(0)$.

1) Langkah pertama. Bentuk Persamaan ke dalam transformasi Laplace.

$\mathcal{L}\{y(t)\}=Y(s)$ dan $\mathcal{L}\{r(t)\}=R(s)$. Dengan menerapkan transformasi Laplace pada kedua ruas persamaan (1), maka dihasilkan:

$$
\begin{gathered}
\mathcal{L}\left\{a y^{\prime \prime}+b y^{\prime}+c y\right\}=\mathcal{L}\{y(t)\} \\
a \mathcal{L}\left\{y^{\prime \prime}\right\}+b \mathcal{L}\left\{y^{\prime}\right\}+c \mathcal{L}\{y\}=R(s) \\
a\left[s^{2} Y(s)-s y(0)-y^{\prime}(0)\right]+b[s Y(s)-y(0)]+c Y(s)=R(s)
\end{gathered}
$$

2) Langkah kedua. Masukkan nilai awal $y(0)$ dan $y^{\prime}(0)$ serta susun persamaan (2) ke dalam $Y(s)$ (persamaan pembantu)

$$
\begin{gathered}
{\left[a s^{2}+b s+c\right]-[a s+b]-a y^{\prime}(0)=R(s)} \\
{\left[a s^{2}+b s+c\right] Y(s)=[a s+b] y(0)+a y^{\prime}(0)=R(s)} \\
Y(s)=\frac{[a s+b] y(0)+a y^{\prime}(0)+R(s)}{\left[a s^{2}+b s+c\right]}
\end{gathered}
$$


3) Langkah ketiga. Jika mengandung pecahan parsial, maka gunakan metode jumlahan pecahan parsial untuk menyelesaikan persamaan (3).

$$
Y(s)=\frac{[a s+b] y(0)+a y^{\prime}(0)}{a s^{2}+b s+c}+\frac{R(s)}{a s^{2}+b s+c}
$$

4) Langkah keempat. Ambil invers transformasi Laplace persamaan (4) maka diperoleh solusi/penyelesaian untuk persamaan (1).

$$
\mathcal{L}^{-1}\{Y(s)\}=y(t)=\mathcal{L}^{-1}\left\{\frac{[a s+b] y(0)+a y^{\prime}(0)}{a s^{2}+b s+c}\right\}+\mathcal{L}^{-1}\left\{\frac{R(s)}{a s^{2}+b s+c}\right\}
$$

Contoh 1. Carilah penyelesaian dari $2 y^{\prime \prime}+4 y^{\prime}-3 y=0$, dengan syarat awal $y(0)=4 \& y^{\prime}(0)=9$. Dengan menggunakan prosedur/ langkah-langkah di atas, maka diperoleh:

$$
\begin{gathered}
\mathcal{L}\left\{2 y^{\prime \prime}+4 y^{\prime}-3 y\right\}=\mathcal{L}\{0\} \\
2 \mathcal{L}\left\{y^{\prime \prime}\right\}+4 \mathcal{L}\left\{y^{\prime}\right\}-4 \mathcal{L}\{y\}=0 \\
2 s^{2} Y(s)-2 s y(0)-2 y^{\prime}(0)+5 s Y(s)-5 y(0)-3 Y(s)=0
\end{gathered}
$$

Untuk $y(0)=4$ dan $y^{\prime}(0)=9$, maka:

$$
\begin{gathered}
2 s^{2} Y(s)-8 s-18+5 s Y(s)-20-3 Y(s)=0 \\
{\left[2 s^{2}+5 s-3\right] Y(s)=8 s+38} \\
Y(s)=\frac{8 s+38}{2 s^{2}+5 s-3}=\frac{8 s+38}{(2 s-1)(s+3)}
\end{gathered}
$$

Menggunakan metode jumlahan pecahan parsial, maka:

$$
\frac{8 s+38}{2 s^{2}+5 s-3}=\frac{A}{(2 s-1)}+\frac{B}{(s+3)}
$$

Diperoleh,

$$
8 s+38=A(s+3)+B(2 s-1)
$$

Untuk $s=-3$ maka $14=-7 B$ atau $B=-2$.

Untuk $s=\frac{1}{2}$ maka $42=\frac{7}{2} A$ atau $A=12$. Jadi,

$$
Y(s)=\frac{8 s+38}{2 s^{2}+5 s-3}=\frac{12}{(2 s-1)}-\frac{2}{(s+3)}
$$

Dengan invers transformasi Laplace didapat,

$$
\mathcal{L}^{-1}\{Y(s)\}=y(t)=\mathcal{L}^{-1}\left\{\frac{12}{(2 s-1)}\right\}-\mathcal{L}^{-1}\left\{\frac{2}{(s+3)}\right\}
$$




$$
\begin{gathered}
y(t)=\mathcal{L}^{-1}\left\{\frac{12}{2\left(s-\frac{1}{2}\right)}\right\}-\mathcal{L}^{-1}\left\{\frac{2}{(s+3)}\right\}=6 \mathcal{L}^{-1}\left\{\frac{2}{2\left(s-\frac{1}{2}\right)}\right\}-2 \mathcal{L}^{-1}\left\{\frac{1}{(s+3)}\right\} \\
y(t)=6 e^{\frac{1}{2} t}-2 e^{-3 t}
\end{gathered}
$$

Jadi, solusi dari persamaan diferensial tersebut yaitu, $y(t)=6 e^{\frac{1}{2} t}-2 e^{-3 t}$.

Contoh 2. Tentukan solusi dari $y^{\prime \prime}-4 y^{\prime}-4 y=8 t$, dengan syarat awal $y(0)=0 \& y^{\prime}(0)=12$. Seperti penyelesaian pada contoh 1 maka diperoleh,

$$
\begin{gathered}
\mathcal{L}\left\{y^{\prime \prime}-4 y^{\prime}-4 y\right\}=\mathcal{L}\{8 t\} \\
\mathcal{L}\left\{y^{\prime \prime}\right\}-4 \mathcal{L}\left\{y^{\prime}\right\}-4 \mathcal{L}\{y\}=8 \mathcal{L}\{t\} \\
s^{2} Y(s)-s y(0)-y^{\prime}(0)-4 s Y(s)+4 y(0)-4 Y(s)=\frac{8}{s^{2}} \\
s^{2} Y(s)-12-4 s Y(s)-4 Y(s)=\frac{8}{s^{2}} \\
\left(s^{2}-4 s-4\right) Y(s)=\frac{8}{s^{2}}+12 \\
Y(s)=\frac{8}{2\left(s^{2}-4 s-4\right)}+\frac{12}{\left(s^{2}-4 s-4\right)} \\
Y(s)=\frac{8}{s^{2}(s-2)^{2}}+\frac{12}{(s-2)^{2}}
\end{gathered}
$$

$Y(s)$ tidak mengandung pecahan parsial, maka langsung ditentukan $y(t)$ yang merupakan solusi yang di inginkan.

$$
y(t)=8 \mathcal{L}^{-1}\left\{\frac{1}{s^{2}(s-2)^{2}}\right\}+12 \mathcal{L}^{-1}\left\{\frac{1}{(s-2)^{2}}\right\}
$$

Untuk $\mathcal{L}^{-1}\left\{\frac{1}{(s-2)^{2}}\right\}=t e^{2 t}$, sedangkan untuk $\mathcal{L}^{-1}\left\{\frac{1}{s^{2}(s-2)^{2}}\right\}$, diselesaikan dengan integral transformasi Laplace.

Telah diketahui $\mathcal{L}^{-1}\left\{\frac{1}{(s-2)^{2}}\right\}=t e^{2 t}$, dan

$$
\mathcal{L}^{-1}\left\{\frac{1}{s^{2}(s-2)^{2}}\right\}=\int_{0}^{t} u e^{2 u} d u=\frac{1}{2} u e^{2 u}-\left.\frac{1}{4} e^{2 u}\right|_{0} ^{t}=\frac{1}{2} t e^{2 t}-\frac{1}{4} e^{2 t}+\frac{1}{4}
$$

Diperoleh,

$$
\mathcal{L}^{-1}\left\{\frac{1}{s^{2}(s-2)^{2}}\right\}=\int_{0}^{t}\left(\frac{1}{2} u e^{2 u}-\frac{1}{4} e^{2 u}+\frac{1}{4}\right) d u
$$




$$
=\frac{1}{4} u e^{2 u}-\frac{1}{4} e^{2 u}+\left.\frac{1}{4} u\right|_{0} ^{t}=\frac{1}{4} t e^{2 t}-\frac{1}{4} e^{2 t}+\frac{1}{4} t+\frac{1}{4}
$$

Jadi,

$$
\begin{gathered}
y(t)=8 \mathcal{L}^{-1}\left\{\frac{1}{s^{2}(s-2)^{2}}\right\}+12 \mathcal{L}^{-1}\left\{\frac{1}{(s-2)^{2}}\right\} \\
y(t)=8\left(\frac{1}{4} t e^{2 t}-\frac{1}{4} e^{2 t}+\frac{1}{4} t+\frac{1}{4}\right)+12 t e^{2 t} \\
y(t)=14 t e^{2 t}-2 e^{2 t}+2 t+2
\end{gathered}
$$

Contoh 3. Diberikan persamaan diferensial, $y^{\prime \prime}-4 y^{\prime}+8 y=8 e^{2 t} \cos 2 t+6 e^{2 t} \sin 2 t$, dengan syarat awal $y(0)=4$ dan $y^{\prime}(0)=10$.

jika kedua ruas ditransformasi ke dalam transformasi Laplace, maka:

$$
\begin{gathered}
\mathcal{L}\left\{y^{\prime \prime}-4 y^{\prime}+8 y\right\}=\mathcal{L}\left\{8 e^{2 t} \cos 2 t+6 e^{2 t} \sin 2 t\right\} \\
s^{2} Y(s)-s y(0)-y^{\prime}(0)-4 s Y(s)+4 y(0)+8 Y(s)=\frac{8(s-2)}{(s-2)^{2}+4}+\frac{6(2)}{(s-2)^{2}+4}
\end{gathered}
$$

Untuk syarat awal $y(0)=4$ dan $y^{\prime}(0)=10$, maka:

$$
\begin{gathered}
\left(s^{2}-4 s+8\right) Y(s)-4 s+6=\frac{8(s-2)}{(s-2)^{2}+4}+\frac{12}{(s-2)^{2}+4} \\
\left((s-2)^{2}+4\right) Y(s)=\frac{8(s-2)}{(s-2)^{2}+4}+\frac{12}{\left[(s-2)^{2}+4\right]^{2}}+\frac{4 s-6}{(s-2)^{2}+4} \\
Y(s)=\frac{8(s-2)}{(s-2)^{2}+4}+\frac{12}{\left[(s-2)^{2}+4\right]^{2}}+\frac{4 s-6}{(s-2)^{2}+4} \\
Y(s)=\frac{8(s-2)}{(s-2)^{2}+4}+\frac{12}{\left[(s-2)^{2}+4\right]^{2}}+\frac{4 s-8+2}{(s-2)^{2}+4} \\
Y(s)=\frac{8(s-2)}{(s-2)^{2}+4}+\frac{12}{\left[(s-2)^{2}+4\right]^{2}}+\frac{4(s-2)}{(s-2)^{2}+4}+\frac{2}{(s-2)^{2}+4}
\end{gathered}
$$

Lalu menggunakan invers transformasi Laplace, maka diperoleh,

$$
\begin{aligned}
y(t) & =8 \mathcal{L}^{-1}\left\{\frac{(s-2)}{(s-2)^{2}+4}\right\}+12 \mathcal{L}^{-1}\left\{\frac{12}{\left[(s-2)^{2}+4\right]^{2}}\right\}+4 \mathcal{L}^{-1}\left\{\frac{(s-2)}{(s-2)^{2}+4}\right\}+\mathcal{L}^{-1}\left\{\frac{2}{(s-2)^{2}+4}\right\} \\
& =\frac{8 e^{2 t}}{4} t \sin 2 t-\frac{8 e^{2 t}}{16}(\sin 2 t-2 t \cos 2 t)+4 e^{2 t} \cos 2 t+e^{2 t} \sin 2 t \\
y(t) & =2 t e^{2 t} \sin 2 t-\frac{3}{2} t e^{2 t} \cos 2 t+4 e^{2 t} \cos 2 t+\frac{7}{2} e^{2 t} \sin 2 t
\end{aligned}
$$




\section{Elemen Rangkaian Listrik Dalam Domain-S}

Untuk dapat mentransformasi suatu rangkaian listrik ke dalam transformasi Laplace, maka perlu didefinisikan elemen-elemen di dalam rangkaian tersebut ke dalam domain-s.

Adapun transformasi elemen-elemen rangkaian listrik ke dalam domain-s didefinisikan sebagai berikut (John Bird, 2007: 640).

1. Resistor $(R)$

Dalam domain waktu $(\mathrm{t})$, resistor didefinisikan oleh hukum Ohm, yaitu:

$$
v_{R}(t)=R i(t)
$$

Transformasi Laplace dari persamaan ini yaitu,

$$
\mathcal{L}\left\{v_{R}(t)\right\}=\mathcal{L}\{R i(t)\}=R I(s)
$$

Diperoleh $v_{R}$ di dalam domain-s,

$$
v_{R}(s)=R i(s)
$$

2. Kapasitor $(C)$

Sebuah kapasitor dalam domain waktu $(t)$ didefinisikan sebagai,

$$
i(t)=C \frac{d v_{c}(t)}{d t} \text { atau } v_{C}(t)=\frac{1}{C} \int i(t) d t
$$

Transformasi Laplace dari persamaan ini yaitu,

$$
\mathcal{L}\left\{v_{C}(t)\right\}=\mathcal{L}\left\{\frac{1}{C} \int i(t) d t\right\}=\frac{1}{C} \frac{I(s)}{s}
$$

Diperoleh impedansi kapasitor dalam domain-s,

$$
v_{C}(s)=\frac{1}{s C} I(t)
$$

3. Induktor $(L)$

Sebuah induktor dalam domain waktu $(t)$ didefinisikaan sebagai,

$$
v_{L}(t)=L \frac{d i(t)}{d t}
$$

Transformasi Laplace dari persamaan ini yaitu,

$$
\mathcal{L}\left\{v_{L}(t)\right\}=\mathcal{L}\left\{L \frac{d i}{d t}\right\}=s L I(s)-\operatorname{Li}(0)
$$

Impedansi Induktor dalam domain-s didefinisikan oleh,

$$
v_{L}(s)=L[s I(s)-i(0)]
$$




\section{Aplikasi Transformasi Laplace Pada Rangkaian Listrik}

Jika diberikan suatu rangkaian listrik, maka prosedur/langkah-langkah untuk mencari penyelesaiannya dengan menggunakan transformasi Laplace yaitu, (John Bird, 2007:642):

1. Gunakan hukum yang berlaku pada rangkaian tersebut untuk menentukan persamaan diferensialnya (Hukum Kirchoff dan hukum Ohm).

2. Ambil transformasi Laplace pada kedua ruas persamaan yang terbentuk.

3. Masukkan nilai awal yang diberikan dan susun persamaan pembantu.

4. Gunakan invers transformasi Laplace untuk menentukan penyelesaiannya.

Contoh 4. Diberikan suatu rangkaian L-R-C seperti pada Gambar 1 tentukan besar arus yang mengalir dalam rangkaian tersebut jika pada saat $t=0$ diberi tegangan sebesar $v$ dan $i(0)=0$.

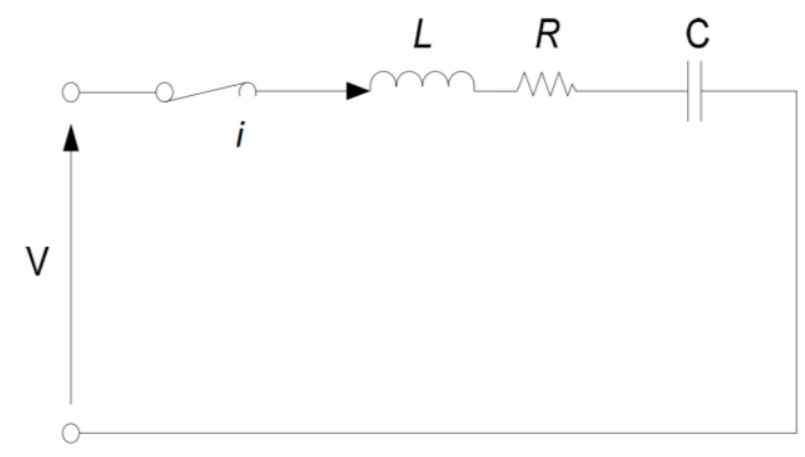

Gambar 1 Rangkaian listrik satu.

Pada rangkaian listrik (Gambar 1) dapat dibentuk sebuah persamaan diferensial dengan menggunakan hukum II Kirchoff yaitu:

$$
\begin{gathered}
\sum v=0 \\
v_{L}+v_{R}+v_{C}-v(t)=0 \text { atau } v(t)=v_{L}+v_{R}+v_{C} \\
v=L \frac{d i(t)}{d t}+R i(t)+\frac{1}{C} \int i(t) d t
\end{gathered}
$$

Ambil transformasi Laplace pada kedua ruas persamaan dan maka diperoleh,

$$
\begin{gathered}
\mathcal{L}\{v\}=\mathcal{L}\left\{L \frac{d i(t)}{d t}+R i(t)+\frac{1}{C} \int i(t) d t\right\} \\
\frac{v}{s}=s L I(s)+L i(0)+R I(s)+\frac{v-s L i(0)}{s\left[s L+R+\frac{1}{s C}\right]}=\frac{v-s L i(0)}{s^{2} L+s R+\frac{1}{C}}
\end{gathered}
$$

Dengan substitusi $i(0)=0$, maka:

$$
\begin{aligned}
I(s)=\frac{v}{s^{2} L+s R+\frac{1}{C}} & =\frac{v}{L\left[s^{2}+s\left(\frac{R}{L}\right)+\frac{1}{L C}\right]} \\
& =\frac{v / L}{s^{2}+s\left(\frac{R}{L}\right)+\frac{1}{L C}}
\end{aligned}
$$


Dengan penggunaan kuadrat sempurna, maka:

$$
\begin{aligned}
I(s) & =\frac{v / L}{\left[s^{2}+\left(\frac{R}{L}\right) s+\left(\frac{R}{2 L}\right)^{2}\right]+\left[\frac{1}{L C}-\left(\frac{R}{2 L}\right)^{2}\right]} \\
& =\frac{v / L}{\left(s+\frac{R}{2 L}\right)^{2}+\left(\sqrt{\frac{1}{L C}-\left(\frac{R}{2 L}\right)^{2}}\right)^{2}} \\
& =\frac{v / L}{\left(s+\frac{R}{2 L}\right)^{2}+\left(\sqrt{\frac{1}{L C}-\left(\frac{R}{2 L}\right)^{2}}\right)^{2} \cdot \frac{\sqrt{\frac{1}{L C}-\left(\frac{R}{2 L}\right)^{2}}}{\left.\sqrt{\frac{R}{2 L}}\right)^{2}}} \\
I(s) & =\frac{v / L}{\sqrt{\frac{1}{L C}-\left(\frac{R}{2 L}\right)^{2}} \cdot \frac{\sqrt{\frac{1}{L C}}-\left(\frac{R}{2 L}\right)^{2}}{\left(s+\frac{R}{2 L}\right)^{2}+\left(\sqrt{\frac{1}{L C}-\left(\frac{R}{2 L}\right)^{2}}\right)^{2}}}
\end{aligned}
$$

Dengan memisalkan $b=\sqrt{\frac{1}{L C}-\left(\frac{R}{2 L}\right)^{2}}$, dan $a=\left(\frac{R}{2 L}\right)$, maka:

$$
I(s)=\frac{v / L}{\sqrt{\frac{1}{L C}-\left(\frac{R}{2 L}\right)^{2}}} \cdot \frac{b}{(s+a)^{2}+b^{2}}
$$

Dengan menggunakan invers transformasi Laplace, maka diperoleh

$$
\begin{aligned}
\mathcal{L}^{-1}\{I(s)\}=i(t) & =\mathcal{L}^{-1}\left\{\frac{v / L}{\sqrt{\frac{1}{L C}-\left(\frac{R}{2 L}\right)^{2}}} \cdot \frac{b}{(s+a)^{2}+b^{2}}\right\} \\
& =\frac{v / L}{\sqrt{\frac{1}{L C}-\left(\frac{R}{2 L}\right)^{2}}} \cdot \mathcal{L}^{-1}\left\{\frac{b}{(s+a)^{2}+b^{2}}\right\} \\
& =\frac{v / L}{\sqrt{\frac{1}{L C}-\left(\frac{R}{2 L}\right)^{2}}} \cdot e^{-a t} \sin b t
\end{aligned}
$$

Jadi, dengan mensubstitusi nilai $a$ dan $b$, maka diperoleh solusi untuk rangkaian pada Gambar 1 di atas yaitu: 


$$
i(t)=\frac{v / L}{\sqrt{\frac{1}{L C}-\left(\frac{R}{2 L}\right)^{2}}} \cdot e^{-\frac{R t}{L}} \sin \left(\sqrt{\frac{1}{L C}-\left(\frac{R}{2 L}\right)^{2}}\right) t(A)
$$

Contoh 5. Tentukan besar arus yang mengalir dalam rangkaian berikut ini jika saklar ditutup pada saat $t=0$.

Gambar 2 Rangkaian listrik dua.

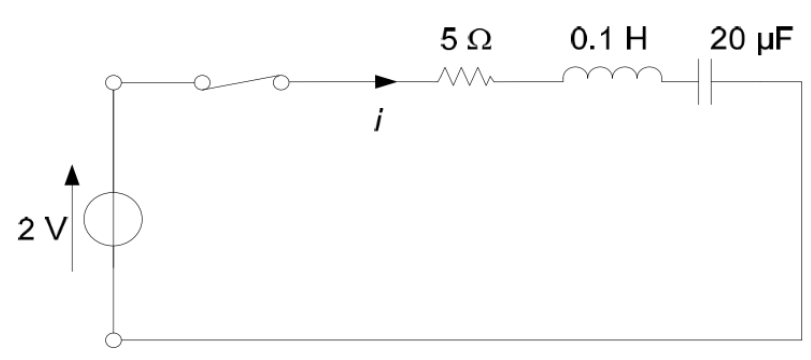

Dengan menggunakan hukum II Kirchoff diperoleh

$$
\begin{gathered}
\sum v=0 \\
v_{L}+v_{R}+v_{C}-v(t)=0 \\
0,1 \frac{d i(t)}{d t}+5 i(t)+\frac{1}{20 \times 10^{-6}} \int i(t) d t-\frac{2}{s}=0
\end{gathered}
$$

Jika ditransformasi ke domain-s maka,

$$
\begin{gathered}
\mathcal{L}\left\{0,1 \frac{d i(t)}{d t}+5 i(t)+\frac{1}{20 \times 10^{-6}} \int i(t) d t-2\right\}=\mathcal{L}\{0\} \\
0,1 s I(s)+0,1 i(0)+5 I(s)+\frac{I(s)}{20 \times 10^{-6} s}-\frac{2}{s}=0 \\
I(s)\left[0,1 s+5+\frac{1}{20 \times 10^{-6} s}\right]=\frac{2}{s}-0,1 i(0)
\end{gathered}
$$

Saklar baru dinyalakan sehingga pada saat awal belum ada arus yang mengalir $(i(0)=0)$. Jadi,

$$
\begin{aligned}
I(s) & =\frac{2}{s\left[0,1 s+5+\frac{5 \times 10^{4}}{s}\right]} \\
& =\frac{2}{\left[0,1 s^{2}+5 s+5 \times 10^{4}\right]} \\
I(s) & =\frac{2}{0,1\left[s^{2}+50 s+5 \times 10^{4}\right]} \\
& =\frac{20}{\left(s^{2}+50 s+5 \times 10^{4}\right)}
\end{aligned}
$$




$$
\begin{aligned}
& =\frac{20}{\left(s^{2}+50 s+(25)^{2}\right)+\left(5 \times 10^{5}-(25)^{2}\right)} \\
& =\frac{20}{(s+25)^{2}+(499375)} \\
& =\frac{20}{(s+25)^{2}+(499375)} \\
& =\frac{20}{(s+25)^{2}+\sqrt{(499375)^{2}}} \\
& =\frac{20}{(s+25)^{2}+(\sqrt{(499375)})^{2}} \cdot \frac{\sqrt{499375}}{\sqrt{499375}} \\
& =\frac{20}{\sqrt{499375}} \cdot \frac{\sqrt{499375}}{(s+25)^{2}+(\sqrt{(499375)})^{2}} \\
& I(s)=\frac{20}{706,7} \cdot \frac{\sqrt{499375}}{(s+25)^{2}+(706,7)^{2}}
\end{aligned}
$$

Diperoleh $i(t)=\mathcal{L}^{-1}\{I(s)\}$, yaitu:

$$
\begin{aligned}
i(t)=\mathcal{L}^{-1}\{I(s)\} & =\mathcal{L}^{-1}\left\{0,0283 \cdot \frac{706,7}{(s+25)^{2}+(706,7)^{2}}\right\} \\
& =0,0283 \cdot \mathcal{L}^{-1}\left\{\frac{706,7}{(s+25)^{2}+(706,7)^{2}}\right\} \\
& =0,0283 \cdot e^{-25 t} \sin 706,7 t(A)
\end{aligned}
$$

Jadi, besar arus listrik yang mengalir pada rangkaian di atas, yaitu: $0,0283 \cdot e^{-25 t} \sin 706,7 t$ Ampere.

Contoh 6. Tentukan besar arus yang mengalir jika saklar ditutup pada saat $t=0$ dalam rangkaian berikut ini!

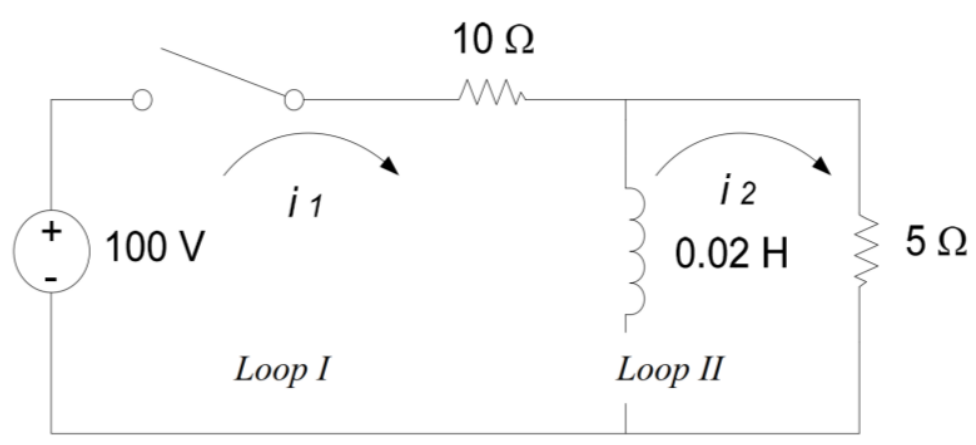

Gambar 3 Rangkaian listrik tiga. 
Dari Gambar 3 diperoleh persamaan dengan menggunakan hukum II Kirchoff:

Persamaan pada loop I:

$$
10 i_{1}+0,02 \frac{d i_{1}}{d t}-0,02 \frac{d i_{2}}{d t}-100=0
$$

Dan persamaan loop II:

$$
0,02 \frac{d i_{2}}{d t}+5 i_{2}-0,02 \frac{d i_{1}}{d t}=0
$$

Jika kedua persamaan ditransformasi ke domain-s, maka diperoleh:

$$
\begin{aligned}
\mathcal{L}\left\{10 i_{1}+0,02 \frac{d i_{1}}{d t}-0,02 \frac{d i_{2}}{d t}-100\right\} & =\mathcal{L}\{0\} \\
10 I_{1}+0,02 s I_{1}(s)-0,02 s I_{2}(s)-\frac{100}{s} & =0 \\
(10+0,02 s) I_{1}(s)-0,02 s I_{2}(s) & =\frac{100}{s}
\end{aligned}
$$

dan

$$
\begin{aligned}
\mathcal{L}\left\{0,02 \frac{d i_{2}}{d t}+5 i_{2}-0,02 \frac{d i_{1}}{d t}\right\} & =\mathcal{L}\{0\} \\
0,02 s I_{2}(s)+5 I_{2}(s)-0,02 s I_{1}(s) & =0 \\
(0,02 s+5)=0,02 s I_{2}(s) & =0
\end{aligned}
$$

Dari persamaan (9), diperoleh

$$
I_{2}(s)=\frac{0,02 s I_{2}(s)}{(0,02 s+5)}=\frac{s}{s+250} I_{1}(s)
$$

Jika persamaan (10) disubstitusikan ke dalam persamaan (8), maka

$$
\begin{aligned}
(10+0,02 s) I_{1}(s)-0,02 s\left(\frac{s}{s+250} I_{1}(s)\right) & =\frac{100}{s} \\
I_{1}(s)\left(10+0,02 s-\frac{0,02 s^{2}}{s+250}\right) & =\frac{100}{s} \\
I_{1}(s)\left(\frac{10 s+2500+0,02 s^{2}+5 s-0,02 s^{2}}{s+250}\right) & =\frac{100}{s} \\
I_{1}(s)(15 s+2500) & =\frac{100(s+250)}{s} \\
I_{1}(s) & =\frac{100(s+250)}{s(15 s+2500)}=\frac{100(s+250)}{15 s(s+166,667)} \\
& =\frac{6,667(s+250)}{s(s+166,667)}
\end{aligned}
$$


Menggunakan metode jumlahan pecahan parsial, maka diperoleh

$$
I_{1}(s)=\frac{6,667(s+250)}{s(s+166,667)}=\frac{A}{s}+\frac{B}{s+166,667} \text { atau } 6,667(s+250)=A(s+166,667)+B s
$$

Untuk $s=0,6,667(250)=A(166,667)$ atau $A=10$

Untuk $s=-166,667,6,667(83,334)=-166,667 B$ atau $B=-3,334$

Jadi, didapatkan nilai $I_{1}(s)$, yaitu:

$$
\begin{gathered}
I_{1}(s)=\frac{s}{s+250}\left(\frac{6,667(s+250)}{s(s+166,667)}\right) \\
I_{2}(s)=\frac{6,667}{(s+166,667)}
\end{gathered}
$$

Dengan menggunakan invers transformasi Laplace maka diperoleh penyelesaian untuk $I_{1}(s)$ dan $I_{2}(s)$ yaitu:

$$
\begin{gathered}
\mathcal{L}^{-1}\left\{I_{1}(s)\right\}=\mathcal{L}^{-1}\left\{\frac{10}{s}-\frac{3,334}{s+166,667}\right\} \\
i_{1}(t)=10-3,334 e^{-166,667 t}(A) \text { dan } \\
\mathcal{L}^{-1}\left\{I_{1}(s)\right\}=\mathcal{L}^{-1}\left\{\frac{6,667}{s+166,667}\right\} \Leftrightarrow i_{1}(t)=10-3,334 e^{-166,667 t}(A) .
\end{gathered}
$$

Contoh 7. Tentukan besar arus yang mengalir jika saklar ditutup pada saat $t=0$ dalam rangkaian berikut ini!

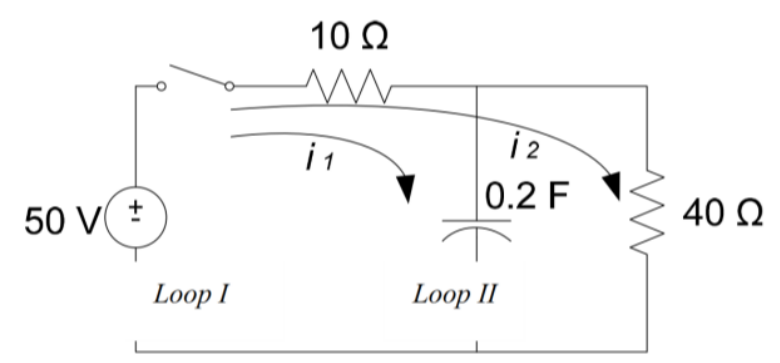

Gambar 4 Rangkaian listrik empat.

Dari Gambar 4 di atas diperoleh persamaan dengan menggunakan hukum II Kirchoff.

Persamaan pada loop I:

$$
10 i_{1}+\frac{1}{0,2} \int i_{1} d t+10 i_{2}=50
$$

Dan persamaan loop II:

$$
10 i_{2}+10 i_{1}=50
$$

Jika kedua persamaan tersebut ditransformasi ke domain-s maka diperoleh persamaan:

$$
10 I_{1}(s)+5 \frac{I_{1}(s)}{s}+10 I_{2}(s)=\frac{50}{s} ; \text { dan }
$$




$$
50 I_{2}(s)+10 I_{1}(s)=\frac{50}{s}
$$

Dari persamaan (13), diperoleh

$$
I_{2}(s)=\frac{50 / s-10 I_{1}}{50}=\frac{1}{s}-0.210 I_{1}(s)
$$

Dengan mensubtitusi persamaan (14) ke dalam persamaan (12), maka:

$$
\begin{aligned}
10 I_{1}(s)+5 \frac{I_{1}(s)}{s}+10\left[\frac{1}{s}-0.210 I_{1}(s)\right] & =\frac{50}{s} \\
I_{1}(s)\left[8+\frac{5}{s}\right] & =\frac{40}{s} \\
I_{1}(s)\left[\frac{8 s+5}{s}\right] & =\frac{40}{s} \\
I_{1}(s) & =40 / 8 s+5=5 / s+0,625
\end{aligned}
$$

Dengan mensubstitusi persamaan (15) ke dalam persamaan (12), maka

$$
\begin{aligned}
I_{2}(s) & =\frac{50}{s}-10 I_{1} / 50 \\
& =1 / 50-0.2[5 / s+0,625]=1 / s-1 / s+0,625
\end{aligned}
$$

Dengan menggunakan invers transformasi Laplace maka diperoleh penyelesaian untuk $I_{1}(s)$, dan $I_{2}(s)$ yaitu:

$$
\begin{gathered}
\mathcal{L}^{-1}\left\{I_{1}(s)\right\}=\mathcal{L}^{-1}\left\{\frac{5}{s+0,625}\right\} \\
i_{1}(t)=5 e^{-0,625 t}(A)
\end{gathered}
$$

Dan

$$
\begin{aligned}
\mathcal{L}^{-1}\left\{I_{2}(s)\right\} & =\mathcal{L}^{-1}\left\{\frac{1}{s}-\frac{5}{s+0,625}\right\} \\
i_{2}(t) & =1-e^{-0,625 t}(A)
\end{aligned}
$$

Contoh 8. Diberikan suatu rangkaian di bawah ini. Saklar $S_{1}$ ditutup pada saat $t=0$, tetapi pada saat yang sama aklar $S_{2}$ dibuka. Tentukan $v_{\text {out }}(t)$ pada saat $t>0$. 


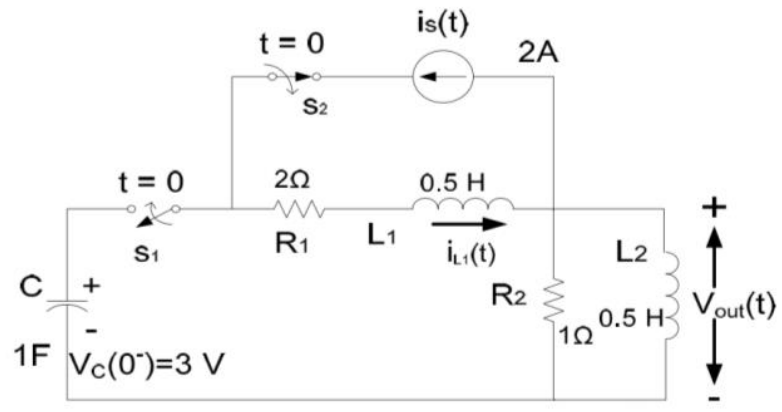

Gambar 5 Rangkaian listrik lima.

Dari rangkaian, terdapat dua kondisi awal yang diberikan yaitu nilai tegangan awal, $v_{C}\left(0^{-}\right)$untuk kapasitor yaitu seberar 3 Volt, dan nilai arus awal sebesar 2 Ampere untuk Induktor $L_{1}$ atau $i_{L 1}\left(0^{-}\right)=$ $2 A$.

Untuk $t>1$, lalu ubah rangkaian gambar 5 ke dalam domain-s seperti berikut.

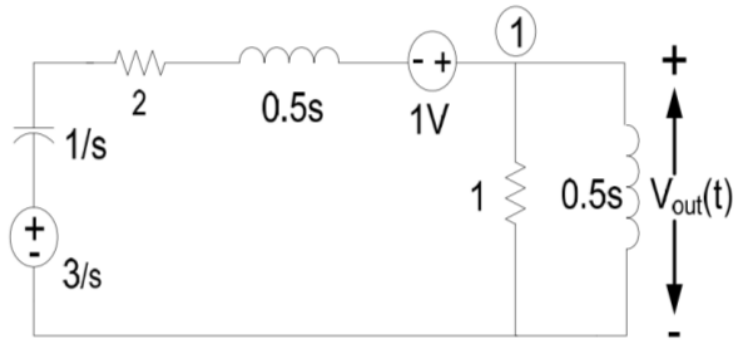

Gambar 6 Rangkaian listrik enam.

Dari gambar 6 arus dalam induktor $L_{1}$ digantikan oleh sumber tegangan $1 \mathrm{~V}$. Ini diperoleh dari $L_{1}$. $i_{L 1}\left(0^{-}\right)=1 V$.

Lalu dengan menggunakan hokum II Kirchoff, diperoleh:

$$
\frac{V_{\text {out }}(s)-1-3 / s}{1 / s-2-s / 2}+\frac{V_{\text {out }}(s)}{1}+\frac{V_{\text {out }}(s)}{s / 2}=0
$$

Kemudian persamaan (17) disederhanakan menjadi

$$
\begin{aligned}
\frac{V_{\text {out }}(s)-1-3 / s}{1 / s-2-s / 2}-\frac{1+3 / s}{1 / s-2-s / 2}+V_{\text {out }}(s)+\frac{2 V_{\text {out }}(s)}{s} & =0 \\
\frac{V_{\text {out }}(s)}{\left(\frac{2-4 s-s^{2}}{2 s}\right)}-\frac{\frac{s+3}{s}}{\left(\frac{2-4 s-s^{2}}{2 s}\right)}+V_{\text {out }}(s)+\frac{2 V_{\text {out }}(s)}{s} & =0 \\
\frac{2 s \cdot V_{\text {out }}(s)}{2-4 s-s^{2}}-\frac{2 s(s+3)}{2-4 s-s^{2}}+V_{\text {out }}(s)+\frac{2 V_{\text {out }}(s)}{s} & =0 \\
\frac{2 s^{2} \cdot V_{\text {out }}(s)}{s\left(2+4 s+s^{2}\right)}-\frac{2 s(s+3)}{s\left(2+4 s+s^{2}\right)}+\frac{V_{\text {out }}(s) s\left(2+4 s+s^{2}\right)}{s\left(2+4 s+s^{2}\right)}+\frac{2 V_{\text {out }}(s)\left(2+4 s+s^{2}\right)}{s\left(2+4 s+s^{2}\right)} & =0 \\
\frac{2 s^{2} \cdot V_{\text {out }}(s)-2 s(s+3)+V_{\text {out }}(s) s\left(2+4 s+s^{2}\right)+V_{\text {out }}(s)\left(4+8 s+2 s^{2}\right)}{s\left(2+4 s+s^{2}\right)} & =0
\end{aligned}
$$




$$
\begin{array}{r}
2 s^{2} \cdot V_{\text {out }}(s)+V_{\text {out }}(s)\left(2 s+4 s^{2}+s^{3}\right)+V_{\text {out }}(s)\left(4+8 s+2 s^{2}\right)=2 s(s+3) \\
V_{\text {out }}(s)\left(2 s^{2}+2 s+4 s^{2}+s^{3}\right)+V_{\text {out }}(s)\left(4+8 s+2 s^{2}\right)=2 s(s+3) \\
V_{\text {out }}(s)\left(s^{3}+8 s^{2}+10 s+4\right)=2 s(s+3) \\
V_{\text {out }}(s)=\frac{2 s(s+3)}{s^{3}+8 s^{2}+10 s+4}
\end{array}
$$

Lalu difaktorkan menjadi

$$
V_{\text {out }}(s)=\frac{2 s(s+3)}{s^{3}+8 s^{2}+10 s+4}=\frac{2 s(s+3)}{(s+6,57)\left(s^{2}+1,43 s+0,61\right)}
$$

Dengan metode jumalahan pecahan parsial didapat

$$
\begin{aligned}
V_{\text {out }}(s) & =\frac{2 s(s+3)}{(s+6,57)\left(s^{2}+1,43 s+0,61\right)}=\frac{A}{(s+6,57)}+\frac{B s+C}{s^{2}+1,43 s+0,61} \\
2 s(s+3) & =A\left(s^{2}+1,43 s+0,61\right)+(B s+C)(s+6,57)
\end{aligned}
$$

Untuk $s=-6,57$ maka

$$
\begin{gathered}
2(-6,57)(-6,57+3)=A\left((-6,57)^{2}+1,43(-6,57)+0,61\right) \\
A=\frac{46,9098}{34,3798}=1,36
\end{gathered}
$$

Untuk $s=0$, dan $\mathrm{A}=1,36$ maka $C=-\frac{0,83}{6,57}=-0,12$.

Untuk $s=1$, dan $A=1,36$ maka $C=-0,12$ diperoleh

$$
\begin{aligned}
2(4) & =1,36(1+1,43+0,61)+(B-0,12)(1+1,36) \\
8 & =4,12+7,57 B-0,96 \\
7,57 B & =4,84 \text { atau } B=0,64 .
\end{aligned}
$$

Diperoleh persamaan baru dari persamaan (19):

$$
\begin{aligned}
V_{\text {out }}(s) & =\frac{1,36}{s+1,36}+\frac{0,64-0,12}{s^{2}+1,43 s+0,61} \\
& =\frac{1,36}{s+1,36}+\frac{0,64 s+(0,46-0,58)}{s^{2}+1,43 s+(0,51+0,1)} \\
& =\frac{1,36}{s+1,36}+0,64 \frac{s+0,715-0,91}{\left(s^{2}+1,43 s+0,51\right)+(0,1)} \\
& =\frac{1,36}{s+6,57}+0,64\left(\frac{s+0,715}{(s+0,715)^{2}+(s+0,316)^{2}}-\frac{0,91}{(s+0,715)^{2}+(0,316)^{2}}\right)
\end{aligned}
$$


Dengan menggunakan invers transformasi Laplace, maka diperoleh penyelesaian dari persamaan rangkaian listrik di atas, yaitu:

$$
\begin{gathered}
\begin{aligned}
\mathcal{L}^{-1}\left\{V_{\text {out }}(s)\right\} & =\mathcal{L}^{-1}\left\{\frac{1,36}{s+6,57}\right\}+\mathcal{L}^{-1}\left\{0,64 \frac{(s+0,715)}{(s+0,715)^{2}+(s+0,316)^{2}}\right\}-\mathcal{L}^{-1}\left\{1,64\left(\frac{0,91}{(s+0,715)^{2}+(0,316)^{2}}\right)\right\} \\
= & \mathcal{L}^{-1}\left\{\frac{1,36}{s+6,57}\right\}+\mathcal{L}^{-1}\left\{0,64 \frac{(s+0,715)}{(s+0,715)^{2}+(s+0,316)^{2}}\right\}-\mathcal{L}^{-1}\left\{1,84\left(\frac{0,316}{(s+0,715)^{2}+(0,316)^{2}}\right)\right\}
\end{aligned} \\
V_{\text {out }}(t)=1,36 e^{-6,57 t}+0,64 e^{-0,715 t} \cos 0,316 t-1,84 e^{-0,715 t} \sin 0,316 t(V)
\end{gathered}
$$

Dari hasil yang diperoleh tersebut, untuk $t \rightarrow \infty$ maka $V_{\text {out }}(t) \rightarrow 0$.

\section{Kesimpulan}

Berdasarkan hasil studi literatur yang dilakukan tentang aplikasi transformasi Laplace pada rangkaian listrik, dapat ditarik kesimpulan sebagai berikut:

1. Transformasi Laplace memiliki manfaat dalam menyelesaikan suatu persamaan diferensial terutama persamaan diferensial linear orde dua dengan koefisien konstan: $y^{\prime \prime}+b y^{\prime}+c y=r(t)$, yaitu secara langsung didapatkan penyelesaian khusus dari nilai awal atau syarat batas yang diberikan.

2. Langkah-langkah untuk mengaplikasikan transformasi Laplace dalam menyelesaikan suatu rangkaian listrik, yaitu: menentukan persamaan diferensial dalam domain- $t$ dari suatu rangkaian listrik dengan menggunakan hukum pada rangkaian tersebut (hukum Ohm atau hukum Kirchoff); membentuk persamaan pembantu dengan menggunakan transformasi Laplace; mensubstitusikan nilai awal atau syarat batas yang diberikan ke dalam persamaan pembantu; menyelesaikan persamaan pembantu dengan perhitungan aljabar, termasuk dengan metode jumlahan pecahan parsial; dan menggunakan invers transformasi Laplace untuk menentukan solusi yang merupakan penyelesaian khusus dari rangkaian listrik tersebut.

\section{Referensi}

[1] Ayres, Frank. 1972. Theory and Problem Of Differential and Integral Calculus, 2nd Edition. New York: McGraw-Hill Companies.

[2] Attenborough, Mary. 2003. Mathematics for Electrical Engineering and Computing. Oxford: Newnes.

[3] Bird, John. 1997. Electrical Circuit Theory and Technology, Third edition. USA: Elsevier Inc.

[4] Budi, Mismail. 1995. Rangkaian Listrik. Bandung: ITB.

[5] Chen, Wai-Kai.2004. The Electrical Engineering Handbook.USA: Elsevier Inc.

[6] Darmawijaya, Soeparna, Dkk._.MATEMATIKA DASAR I. Yogyakarta: Universitas Gadjah Mada.

[7] Dedy, Endang, dkk. 2003. KALKULUS I. Bandung: JICA.

[8] Fidiyah, Suci. 2006. Aplikasi Transformasi Laplace pada Penyelesaian Persamaan Aliran Panas dan Persamaan Gelombang. Malang: UMM.

[9] Farlow, Stanley J. 1994. Partial Differential Equations for Scientists and Engineers. New York: John Wiley Inc.

[10] Gazali, Wikaria dan Soedadyatmodjo. 2007. KALKULUS Edisi kedua. Yogyakarta: Graha IImu.

[11] Harini, Meyriska Aulia. 2005. Transformasi Laplace dari masalah Nilai Batas pada Persamaan Diferensial Parsial. Semarang: FMIPA UNNES.

[12] Havil, Julian. 2003. Gamma: Exploring Eulers Constant.New Jersey: Princeton University.

[13] Holbrook, James G. 1959. Laplace Transforms for Electronic Engineers. NewYork: Pregamon Press.

[14] Karris, Steven T. 2006. Circuit Analysis // with MATLAB' Computing and Simulink' / SimPowerSystem' Modeling. California: Orchard publications.

[15] Logan, J. David. 2006. A First Course in Differential Equations. USA: Spinger.

[16] Maxfield, Clive, dkk. 2008. Electrical Engineering, Know It All. USA: Elsevier Inc.

[17] Nahvi, Mahmood and Joseph A. Edminister. 1986. Theory and Problem Of Electric Circuits, fourth Edition. New York: McGraw-Hill Companies.

[18] Prayudi. 2006. Matemamatika Teknik Edisi Pertama. Yogyakarta: Graha Ilmu.

[19] Powell, Ray. 1995. Introduction to Electric Circuits. London: Arnold. 
[20] Power, David L. 2006. Boundary Value Problem and Partial Differential Equations, Fifth Edition. USA: Elsevier Inc.

[21] Purcell, Edwind J. 1984. Calculus with Analytic Geometry, 4th Edition. Arizona: Prentice-Hall.

[22] Ramdhani, Mohammad. 2005. Rangkaian Listrik. (Diktat Kuliah). Bandung: STT Telkom.

[23] Rahardi, Rustanto, Herman Hudojo dan Imam Supemo. 2003. Persamaan Diferensial Biasa. Malang: UNM.

[24] Spiegel, Murray, R. 1965. Laplace Transformation, Schaums Series. New York: Mc Graw-Hill Companies.

[25] Stourd, K.A. dan Dexter J. Both. 2003. Engineering Mathematics, Fifth Edition. New York: Mc Graw-Hill.

[26] Udiansari, Risqi. 2009. Menyelesaikan Getaran Pegas dengan Transformasi Laplace. Malang: FMIPA-UMM.

[27] Varberg, Dale dan Steven E. Rigdon. 2001. Calculus. New York: Hamline University. 